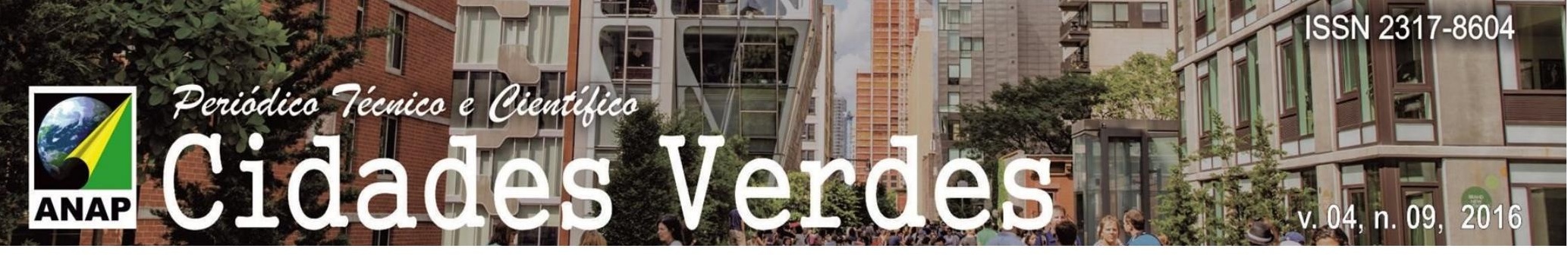

\title{
AÇÕES SUSTENTÁVEIS EM MEGAEVENTOS ESPORTIVOS - O CASO DOS JOGOS OLÍMPICOS E PARALÍMPICOS RIO 2016
}

Sustainable actions in Sports Megaevents - The case of the Olympic and Paralympic Games Rio 2016

Acciones sostenibles en grandes eventos desportivos - El caso de los Juegos Olímpicos y Paralímpicos Río 2016

Priscila Oliveira Engenheira de Produção, UNESA, Brasil priscila.oliveira@ufrj.br 


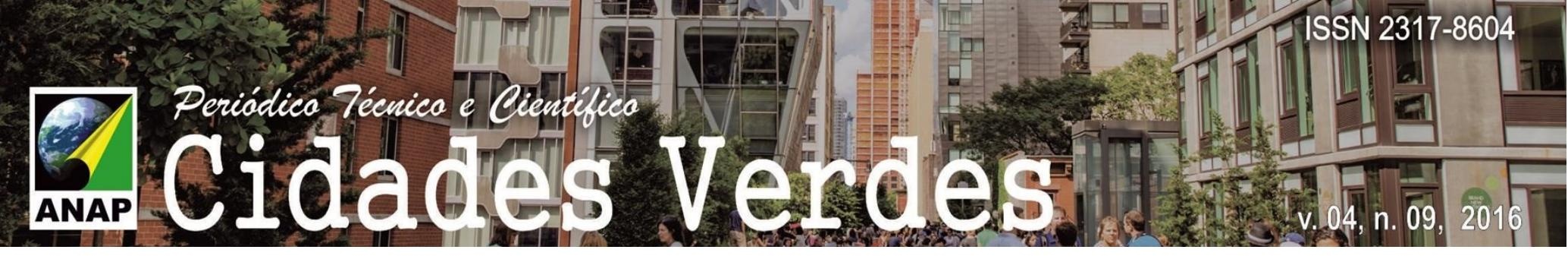

\section{RESUMO}

Os megaeventos esportivos a serem realizados na cidade do Rio de Janeiro são mobilizadores de mudanças profundas na infraestrutura e dinâmica da cidade, mobilizando a população, atletas, a força de trabalho e o contigente de voluntariado, deixando um legado de sensíveis modificações na paisagem urbana, de investimentos em estruturas físicas para abarcar os jogos, de revitalização da rede hoteleira, aeroportos, rede rodoviária e ferroviária, e investimentos em segurança pública. Dessa forma o poder público e a iniciativa privada veem a necessidade cada vez mais crescente de engajar tais mudanças numa realidade sustentável, que articule tais eventos às premissas de promoção de melhoria da qualidade de vida das pessoas e do meio ambiente. Sob tal enfoque, a presente pesquisa visa investigar as principais ações sustentáveis presentes no planejamento e execução dos Jogos Olímpicos e Paralímpicos Rio 2016, a serem realizados na cidade do Rio de Janeiro, em 2016. E, após o estudo bibliográfico sobre os principais conceitos norteadores da pesquisa e de consulta aos documentos de domínio público como prestação de informação e tranparência dos Jogos presentes no site do Comitê Rio 2016, foram identificados, mapeados e analisados um total de nove pilares de processos, com enfoque em ações sustentáveis, no tocante à redução de impactos ambientais via o gerenciamento eficaz e redução de resíduos, da construção de instalações verdes, da sensibilização e conscientização de stakeholders no engajamento e participação em iniciativas que visem a preservação do meio ambiente.

PALAVRAS-CHAVE: Sustentabilidade. Megaeventos Esportivos. Eventos Verdes.

\section{ABSTRACT}

The sports megaevents to be held in the city of Rio de Janeiro mobilize profound changes in the infrastructure and dynamics of the city, they engage the population, athletes, workforce and volunteeres, and leave a legacy of sensitive changes in the urban landscape, they promote investments in infrastructure in the games's areas, the revitalization of the hotel network, airports, road and rail network. Thus the government and the private sector see the ever-increasing need to engage these changes in a sustainable reality to improve the quality of life of the population and preserve the environment. Under this approach, the present study aims to investigate the main sustainable actions present in the planning and execution of the Olympic and Paralympic Games Rio 2016, to be held in the city of Rio de Janeiro in 2016. And after the bibliographical study concerning the main guinging concepts and the consulting of the public domain documents found in Rio 2016 website, it was possible to identify and analyze a total of nine pillars processes, focused on sustainable actions such as reducing environmental impacts through effective management of waste, the construction of green facilities and the engagement and participation of the stakeholders in initiatives to preserve the environment.

KEYWORDS: Sustainability. Sports megaevents. Green events.

\section{RESUMEN}

Los grandes eventos deportivos que se celebrarán en la ciudad de Río de Janeiro reconfiguran la infraestructura de la ciudad, reúnen la gente, atletas, trabajadores y voluntarios, dejando un legado de cambios sensibles en el paisaje urbano con la revitalización de la red de hoteles, aeropuertos, transporte y la inversión en la seguridad publica. Así, el gobierno y el sector privado ven la necesidad de tener en cuenta estos cambios en una realidad sostenible, para mejorar la calidad de vida y el medio ambiente. Bajo este enfoque, el presente estudio tiene como objetivo investigar las principales acciones sostenibles presentes en la planificación y ejecución de los Juegos Olímpicos Rio 2016, que acontecerán en la ciudad de Río de Janeiro en 2016. Y después del estudio bibliográfico acerca de los conceptos fundamentales de la investigación y la consulta de los documentos presentes en el website de Río 2016, fueron identificados nueve procesos centrándose en acciones sostenibles, acerca de la reducción de los impactos ambientales a través de una gestión eficaz y la reducción de residuos, la construcción de instalaciones verdes, y la participación de la gente en iniciativas para preservar el medio ambiente.

PALABRAS CLAVE: Sostenibilidad. Megaeventos deportivos. Eventos verdes. 


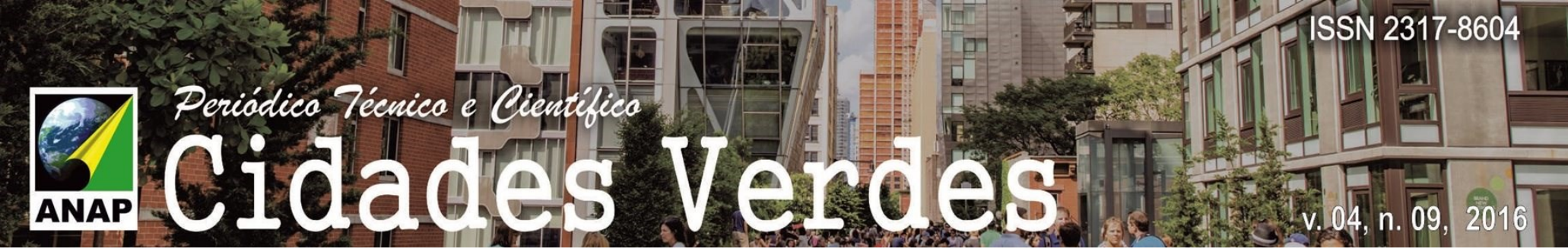

\section{INTRODUÇÃO}

Os megaeventos esportivos a serem realizados na cidade do Rio de Janeiro, em 2016, são mobilizadores de mudanças profundas na infraestrutura e dinâmica da cidade, mobilizando a população, atletas, a força de trabalho e voluntariado, deixando um legado de grandes mudanças na paisagem urbana, investimentos em estruturas para abarcar os jogos, revitalização de infraestrutura de transporte e rede hoteleira e investimentos na segurança pública.

E, dessa forma, cada vez mais as organizações privadas e o poder público veem a necessidade de engajar tais mudanças numa realidade sustentável, que articule tais eventos às premissas de promoção de melhoria da qualidade de vida das pessoas e do meio ambiente.

Assim, vê-se no planejamento e execução de tais eventos a oportunidade de praticar determinadas ações que visem reduzir os impactos ambientais advindos da realização dos mesmos, proporcionar maior economia e benefícios para a população do entorno, estabelecendo um relacionamento harmônico entre as partes.

Sob tal premissa, a presente pesquisa visa investigar as principais ações cujos objetivos sejam atuar em práticas sustentáveis presentes no planejamento e execução dos Jogos Olímpicos e Paralímpicos Rio 2016, a serem realizados na cidade do Rio de Janeiro, em 2016. E, para tanto, utilizou-se da pesquisa de cunho bibliográfico para a delimitação do conceito de sustentabilidade e do engajamento do mesmo numa realidade voltada a megaeventos esportivos, utilizou-se também da consulta a documentos gerados pelo Comitê organizador desses jogos, disponibilizados no site do Rio 2016 (www.rio2016.com), no que concernem às práticas sustentáveis aplicadas ao gerenciamento dos processos internos e externos ao evento.

Como resultados obtidos foram identificados, mapeados e analisados um total de nove pilares de processos, embebidos em práticas sustentáveis, no tocante à redução de impactos ambientais via o gerenciamento eficaz e redução de resíduos, da construção de instalações verdes, da sensibilização e conscientização de stakeholders no engajamento e participação em iniciativas que visem a preservação do meio ambiente.

\section{SUSTENTABILIDADE EM MEGAEVENTOS ESPORTIVOS}

De acordo com Silva (2009), a partir da década de 1980 os países tomam maior conscientização em abarcar práticas sustentáveis para a promoção de um desenvolvimento que reduzisse os efeitos negativos sobre o Meio e garantisse uma melhor qualidade de vida para as próximas gerações. Pereira e Alves (2015) apud Matias (2011) corroboram da visão supracitada, agregando a noção de crescente preocupação das organizações em ativar estratégias de gerenciamento de processos capazes de minimizar impactos negativos ao Meio, por meio da união da questão da responsabilidade social à sustentabilidade.

Nesse contexto, Montibeller-Filho (2004) define sustentabilidade como um processamento de melhoria contínua de condição da vida humana, das pessoas e povos, no qual haja a visão e estratégias que privilegiem a minimização do uso de recursos naturais, promovendo a 


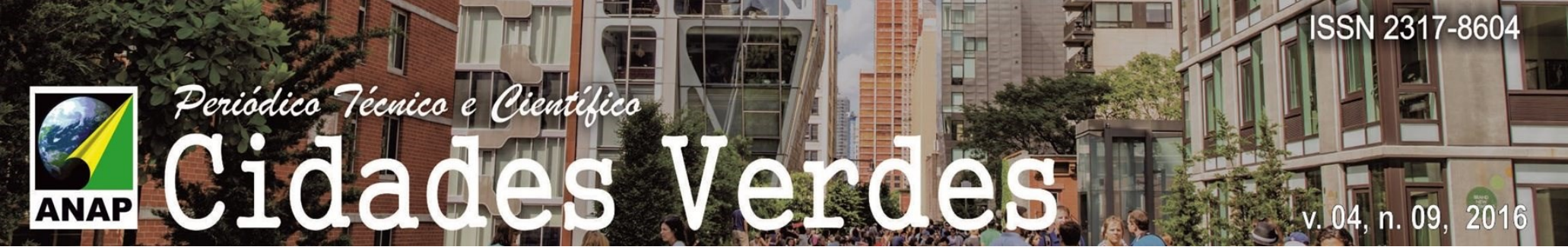

- Econômico - Pilar viabilizador para o acontecimento, mobilização e implementação de projetos.

Dessa forma, o planejamento de megaeventos esportivos baseado em premissas verdes, ou seja, comprometidos com práticas e vieses mais sustentáveis, torna-se fundamental para a redução dos impactos negativos desses eventos passageiros no meio ambiente e da maximização das influências positivas no mesmo, visando um horizonte de curto, médio e longo prazo.

Sob tal enfoque, compilou-se, a seguir, a sumarização adaptada de ações sustentáveis para a promoção de eventos verdes, vista indagações de Piccin et al. (2011), Santos (2011) e Philippi Jr. et al (2010) organizadas por Pereira e Alves (2015):

- Construção de edificações mais sustentáveis - Por meio de implementação de tecnologia de redução de vazão e de menor consumo, com sistema de captação de agua da chuva;

- Uso de metodologia para pesquisa do melhor local para sediar o evento - Com foco na redução de movimentações e grandes deslocamentos;

- Minimização de impactos ambientais via escolha da adequada localização do evento Foco no uso racional do espaço físico diante da quantidade de participantes prevista para o evento;

- Escolha estratégica dos fornecedores de matérias e serviços - Com priorização de fornecedores mais próximos para reduzir danos ambientais por longos transportes e movimentações;

- Adequada destinação de resíduos e neutralização/redução de emissões de carbono (CO);

- Reduzir, reciclar e reutilizar resíduos, sempre que possível;

- Reduzir desperdícios.

Nesse sentido, a presente pesquisa investigará ações embebidas no conceito da sustentabilidade praticadas na organização dos Jogos Olímpicos e Paralímpicos Rio 2016, sob a premissa da busca do equilíbrio entre as esferas sociais, ambientais e econômicas no planejamento e realização de tais megaeventos.

\section{OBJETIVOS}

A pesquisa tem como principais objetivos:

- Identificar e analisar as ações sustentáveis presentes nas atividades do poder público para a preparação da cidade do Rio de Janeiro para a recepção dos Jogos Olímpicos e Paralímpicos Rio 2016;

- Contribuir com a literatura técnica e o legado em megaeventos esportivos sob a perspectiva verde. 


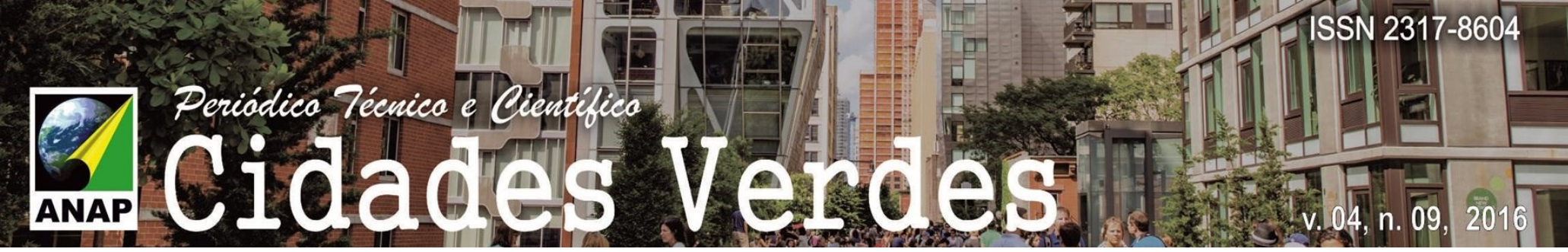

\section{METODOLOGIA}

A metodologia de pesquisa fez-se por meio da realização dos seguintes passos:

a) Levantamento bibliográfico acerca da sustentabilidade aplicável em megaeventos esportivos, para subsidiar o melhor entendimento da pesquisa;

b) Consulta a relatórios técnicos, de domínio público, confeccionados pelo comitê Olímpico Rio 2016 (www.rio2016.com) em relação ao planejamento dos jogos na cidade-sede do Rio de Janeiro;

c) Identificação, mapeamento e análise das práticas sustentáveis presentes nesses relatórios técnicos e

d) Obtenção descritiva das ações sustentáveis presentes no planejamento dos Jogos Olímpicos e Paralímpicos Rio 2016.

\section{RESULTADOS}

Como resultados, foram selecionadas as principais práticas sustentáveis coletadas no site Rio2016, expostas nos seguintes documentos:

- Diagnóstico para oferta de alimentos saudáveis e sustentáveis nos Jogos Olímpicos e Paralímpicos (2014);

- Guia da Cadeia de Suprimentos Sustentável (2014);

- Material destinado aos Caterings dos Jogos Olímpicos e Paralímpicos Rio 2016 (2016);

- Plano de Gestão Ambiental das Instalações (2014);

- Plano de Gestão da Sustentabilidade (PGS) dos Jogos Rio 2016 (2013);

- Política de Resposta à Emergência Ambiental (2014);

- Relatório de Gestão da Pegada de Carbono dos Jogos Rio 2016 (2014);

- Relatório de Sustentabilidade Rio 2016 (2014);

- PGS - Estratégia de Sustentabilidade (2016) e

- Olympic Games Impact Study - RIO 2016 (2014).

E, por meio do estudo desses documentos, foram compilados os nove principais pilares mobilizadores das ações sustentáveis implementadas junto ao processo de planejamento e execução dos Jogos Olímpicos e Paralímpicos Rio 2016:

Acessibilidade e Inclusão Social - Priorizou-se a construção de instalações promotoras de acesso facilitado a todos os tipos de sujeitos, inclusos deficientes físicos e visuais, segundo normativas e requisitos ABNT. Criou-se o programa "Sobre Rodas Rio 2016" cujo objetivo principal foi sensibilizar os colaboradores que não possuem deficiência a vivenciar, por um dia, a realidade da vida de um cadeirante. Criou-se também um grupo para verificar a acessibilidade em hotéis no Rio de Janeiro, totalizando 67 avaliações, para avaliar o grau de acessibilidade das acomodações para turistas na cidade e promover a conscientização do oferecimento de estruturas adaptadas para a mobilidade contínua. Criaram-se grupos de 


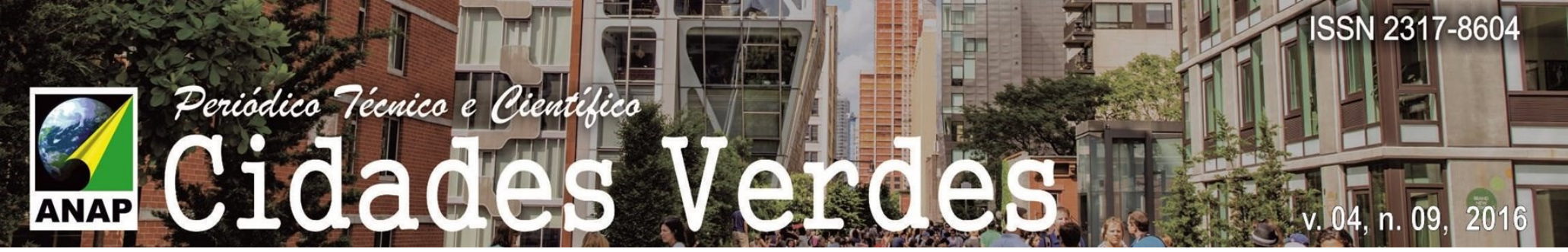

diálogo para incorporar os gêneros, LGBT, negros e pessoas com deficiência, com a finalidade de propor ações em beneficio das causas sociais em todos os processos internos do Comitê Organizador. Instaurou-se o "Programa de Diversidade para recrutamento e contratação de mão de obra" e o "Programa de Treinamento para Diversidade, Inclusão e Acessibilidade", que envolvem funcionários, estagiários e voluntários, voltado para a capacitação de pessoal no tocante à temática da diversidade, inclusão e acessibilidade, sendo sua realização de caráter obrigatório;

Construções mais verdes - Para a sede do Rio 2016, localizada no bairro de Cidade Nova, na cidade do Rio de Janeiro, priorizou-se o tipo de construção sustentável, de cunho temporário, que visa o desmonte para tão logo termine o evento. $\mathrm{E}$, cerca de $80 \%$ dos materiais serão reutilizados em futuras instalações, garantindo o consumo de $70 \%$ menos energia se comparado às instalações comuns. Utilizou-se também o sistema inteligente de economia de água em banheiros, cozinhas e refeitórios, por temporização, em pias e descargas, que garante um consumo racional da água. Conta também com o sistema de captação de água da chuva, permitindo o reuso da mesma em banheiros e jardins;

Integração de Stakeholders - A integração dos stakeholders foi uma das preocupações para a realização do megaevento e foram incorporados diálogos com representantes de organizações com a finalidade de análise do conteúdo do PGS, promoveu-se também cerca de 13 encontros com a sociedade civil para discussão de temas concernentes à proteção da criança e do adolescente, à acessibilidade e à transparência. Como também o grupo temático "Rio Alimentação Sustentável", criado em 2013, visando o envolvimento do poder público, iniciativa privada e a população para criação de um legado de eventos que promova a difusão de alimentos saudáveis e sustentáveis, na intenção de propor melhorias para tal setor da economia no pais;

Gerenciamento dos Resíduos - Devido ao alto volume dos resíduos gerados em megaeventos esportivos, tornou-se essencial o eficaz gerenciamento dos mesmos, e para tanto trabalhou-se em políticas de sensibilização de espectadores, colaboradores e atletas para o descarte correto e consciente de resíduos. Criou-se o "Programa de Reciclagem Inclusiva: Catadores nos Jogos Rio 2016", composto por 240 catadores e 33 cooperativas, advindo de uma parceria entre Redes de Organizações de Catadores de Materiais Recicláveis do Estado do Rio de Janeiro, o Comitê Rio 2016, o Ministério do Trabalho e Emprego (MTE), a Secretaria de Ambiente do Estado do Rio de Janeiro (SEA) e empresas da iniciativa privada, que visa a promoção da conscientização da prática da separação correta do lixo e da reciclagem durante os Jogos Rio 2016 de modo a criar um legado para as edições futuras dos mesmos. Criou-se também o "Guia de Sustentabilidade para Embalagens", no qual constam os requerimentos de sustentabilidade, tanto os de cunho obrigatório quanto os de cunho opcionais, para o rótulo, o eco design, sobre a acessibilidade no tocante à informação, sobre os materiais utilizados na embalagem;

Gerenciamento da Sustentabilidade - A gestão da sustentabilidade junto ao planejamento dos Jogos foi certificada pela ISO estando em harmonia com os critérios da normativa técnica ABNT NBR 20121 (2012), no que concerne à padronização de parâmetros para o gerenciamento de eventos sustentáveis, do maior engajamento dos processos de inclusão social, responsabilidade social, ambiental e econômica, da ética e da transparência. E, sob tal perspectiva, foram gerados três relatórios de sustentabilidade que permeiam os três principais 


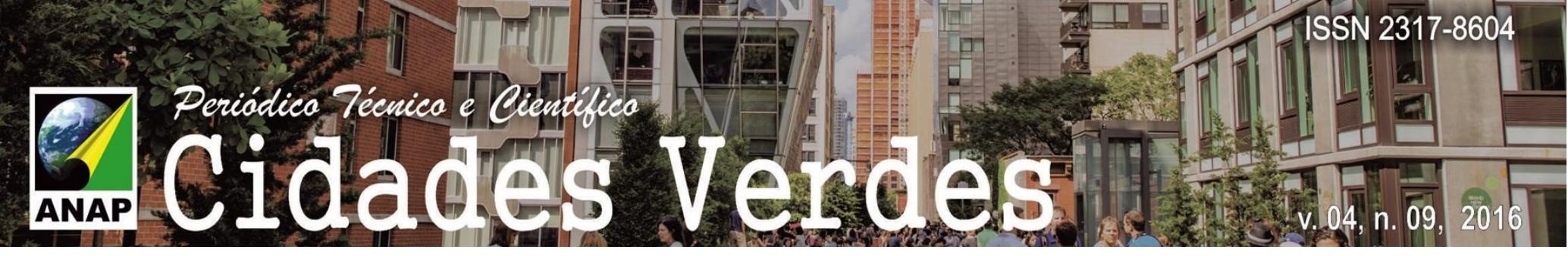

períodos do megaevento: o período de organização, o período de realização e o período de desmonte. Tais estudos foram compilados nos documentos "Relatório de Sustentabilidade", no "Plano de Gestão da Sustentabilidade" e no "Estudo de Impactos dos Jogos Olímpicos", citados anteriormente;

Pegada de carbono - Segundo as informações coletadas no site do Rio 2016, visou-se a entrega de um megaevento de baixo impacto e para isso foram trabalhadas iniciativas para reduzir as emissões de carbono. Gerou-se um relatório do estudo realizado sobre a pegada de carbono e o gerenciamento dessas emissões, com foco no processamento de medição do impacto, na redução das emissões e em mitigar, quando possível, e compensar no que não puder sê-lo mitigado;

Propagação do conhecimento e agentes multiplicadores - Uma das premissas dos Jogos Rio 2016 trata-se da propagação do conhecimento e da qualificação de agentes multiplicadores de informação. Segundo informações obtidas no site do comitê, foi criado o "Programa Transforma: Educação nas Escolas", cujo objetivo principal é inserir os Jogos 2016 em escolas para que os alunos vivenciem os valores dos mesmos, experimentem esportes e se engajem nos eventos. Esses dados foram compilados na tabela 1, a seguir.

Tabela 1: Compilação dos dados do Programa Transforma - Educação nas Escolas

\begin{tabular}{|c|c|c|c|}
\hline Participantes & $\begin{array}{l}\text { Dezembro } \\
2014\end{array}$ & $\begin{array}{l}\text { Dezembro } \\
2015\end{array}$ & Março 2016 \\
\hline Escolas engajadas & 260 & 5,886 & 10,058 \\
\hline Estudantes participando das atividades & 100,000 & $4,816,455$ & $5,839,122$ \\
\hline $\begin{array}{l}\text { Professores (coordenadores pedagógicos, } \\
\text { professores de educação física, mentores) }\end{array}$ & 902 & 5,176 & 25,035 \\
\hline Número de agentes jovens participando & 1,448 & 4,600 & 5,730 \\
\hline
\end{tabular}

Fonte: Comitê Olímpico Rio 2016 (https://www.rio2016.com), 2016

Segundo dados obtidos ainda na web Page do comitê, foi criado também o programa de capacitação de voluntários, abarcando mais de 50 mil voluntários, que oferece mais de 1600 cursos de capacitação e idiomas;

Uso racional e consciente de materiais - Segundo o website Rio 2016, foram priorizadas a utilização de materiais certificados, reutilizáveis e recicláveis. Fez-se também o uso de madeira certificada, o que garantiu a manipulação sustentável da extração, como também a 


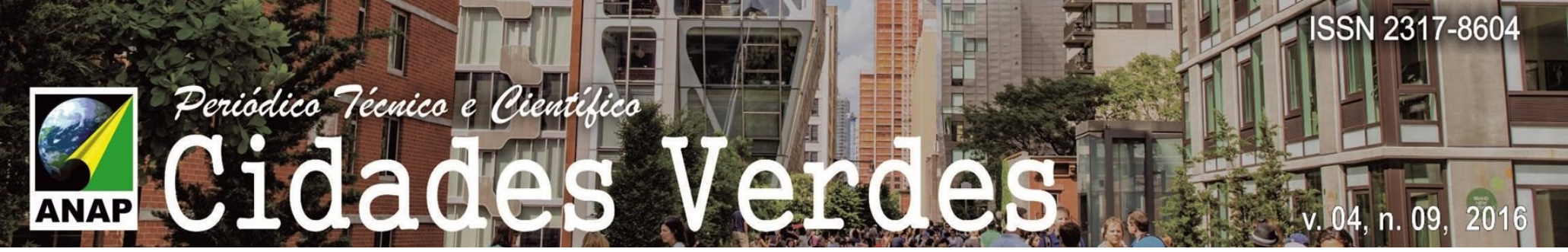

rastreabilidade da mesma desde o momento da saída do produto da floresta ate a chegada ao consumidor final;

Supply Chain Sustentável - Buscou-se, nas atividades de planejamento e execução dos Jogos, o gerenciamento eficiente da cadeia de suprimentos visando a busca de vantagem competitiva, aliada à práticas sustentáveis. E, como legado, criou-se o "Guia da Cadeia de Suprimentos Sustentável", citado anteriormente, que busca inserir os pilares da sustentabilidade junto aos requerimentos técnicos das contratações de fornecedores. Implementou-se também a rotina de monitoramento da supply chain, de modo a acompanhar critérios de sustentabilidade e investir em gerenciamento de risco em relação aos fornecedores da cadeia, via visitas técnicas às unidades fabris e a verificação e monitoramento da conformidade ambiental, social e ética durante a produção. Criou-se também o "Guia de Compras Sustentáveis" que trata-se de uma metodologia de sustentabilidade para o gerenciamento da cadeia de fornecedores.

\section{CONLUSÃO}

Com o advento dos megaeventos esportivos e o considerável aumento da realização desses no Brasil, faz-se necessário atentar-se para a importância da realização de eventos mais sustentáveis. Vale ressaltar que tais eventos são passageiros e que devem, a partir de uma premissa verde, reduzir impactos negativos e maximizar os positivos para reversão de benefícios para a sociedade.

Por meio dos resultados obtidos, através da pesquisa de cunho bibliográfico, mostra-se cada vez mais crescente a preocupação em gerenciar megaeventos de forma mais sustentável, que estejam em consonância com normas técnicas, tal como a ABNT NBR 20121 (2012), no tocante aos processos de gerenciamento da sustentabilidade na promoção dos eventos, seguindo premissas de redução de resíduos e de valorização da reciclagem e reuso de materiais, com o uso de materiais renováveis em estruturas sustentáveis, com a sensibilização e o engajamento de pessoas e organizações na implementação de estratégias mais verdes, visando a redução de impactos negativos ao Meio e a melhoria contínua da qualidade de vida da população atual, atrelado aos interesses das futuras gerações.

\section{REFERÊNCIAS BIBLIOGRÁFICAS}

ABNT - ASSOCIAÇÃO BRASILEIRA DE NORMAS TÉCNICAS (2012). NBR 20121: Sistemas de Gestão para Sustentabilidade de Eventos - Requisitos com Orientações de Uso. Rio de Janeiro, ABNT.

ISO (2012). Sustainable events with ISO 20121. Disponivel em: http://www.iso.org/iso/sustainable_events_iso_2012.pdf. Capturado em 15 de maio de 2016.

MATIAS, M. (2008). Os efeitos dos megaeventos esportivos nas cidades. In: Revista Turismo \& Sociedade, V 1, N.2 ISSN: 1983-5442.

MATIAS, M. (2011) Planejamento, Organização e sustentabilidade em eventos: Culturais, sociais e esportivos. Barueri, Manole. 
